DOI: $10.3901 / J M E .2019 .14 .053$

\title{
锂离子动力电池低温复合加热方法*
}

\author{
熊 瑞 王 㑆 郭姗姗 \\ (北京理工大学机械与车辆学院 北京 100081)
}

\begin{abstract}
摘要: 锂离子动力电池低温环境下充放电性能差, 充电过程可能发生析锂, 甚至引发安全事故, 因此, 开展锂离子动力电 池低温加热必要且紧迫。为实现锂离子动力电池低温快速加热, 提出一种结合交流电内部加热和宽线金属膜外部加热的复 合加热方法, 建立动力电池的温升模型, 仿真分析动力电池的温升特性, 基于此, 开展动力电池低温复合加热策略的验证 试验。结果表明, 复合加热法可以在 $471 \mathrm{~s}$ 内将动力电池从 $-20{ }^{\circ} \mathrm{C}$ 加热到 $5{ }^{\circ} \mathrm{C}$, 相较于交流电加热法加热速率提升 $22 \%$ 、 加热功耗降低 $23 \%$; 对单体内阻差异较大的电池组, 该方法还能提升加热效果的一致性, 是一种可行的动力电池系统低温 加热方法。
\end{abstract}

关键词: 锂离子动力电池; 低温复合加热策略; 宽线金属膜加热; 交流电加热

中图分类号: TM912

\section{Hybrid Preheating Method for Lithium-ion Battery Used in Cold Environment}

\author{
XIONG Rui WANG Kan GUO Shanshan
}

(School of Mechanical Engineering, Beijing Institute of Technology, Beijing 100081)

\begin{abstract}
Due to the poor charge-discharge performance of lithium-ion batteries and the lithium precipitation during the charging process in cold environment, which may even result in safety accidents, it is necessary and urgent to preheat lithium-ion batteries in subzero temperature. In order to realize the low-temperature rapid heating of lithium-ion battery, a hybrid heating method combining internal heating of $\mathrm{AC}$ and external heating of wide-wire metal film is proposed. The temperature rise model of the battery is established to simulate the temperature rise characteristics. Therefore, the verification test of the hybrid heating strategy is carried out. The results show that the hybrid heating method can heat the battery from $-20{ }^{\circ} \mathrm{C}$ to $5{ }^{\circ} \mathrm{C}$ in $471 \mathrm{~s}$. Compared with the AC heating method, the heating rate is increased by $22 \%$, and the heating power consumption is reduced by $23 \%$. Especially for battery pack with large difference in its cell's internal resistance, the method can also improve the consistency of the heating effect, and thus is a feasible low-temperature heating method for the battery system.
\end{abstract}

Key words: lithium-ion battery; hybrid heating method; wide-wire metal film heating; AC heating

\section{0 前言}

锂离子动力电池凭借其能量密度高、工作电压 高、贮存寿命长、功率密度高等优势在电动汽车领域 被广泛应用。然而锂离子动力电池低温下充放电性能 较差, 充电时可能导致发生析锂, 严重时会形成锂枝 晶, 刺穿电池隔膜, 引发内部短路, 导致电池失效甚 至起火, 对汽车和驾驶者的安全危害极大 ${ }^{[1-3]}$ 。这一问

* 国家重点研发计划资助项目(2018YFB0104100)。20190326 收到初稿, 20190612 收到修改稿
题严重制约了锂离子动力电池乘用车的进一步发 展, 特别是电动汽车在高寒地区的普及化。因此, 需要开展锂离子动力电池低温加热方法研究, 提升 其低温下的充放电性能, 并防止析锂现象和安全事 故的发生 ${ }^{[4]}$ 。

为了改善锂离子动力电池的低温加热效果, 国 内外学者研究了多种实现锂离子动力电池低温加 热的方法, 如图 1 所示, 主要分为两类, 内部加热 法和外部加热法。其中外部加热方法涵盖了空气加 热法、宽线金属膜加热法以及其他外部加热方式; 内部加热方法则主要包括交流电加热法和内部自 加热法。 


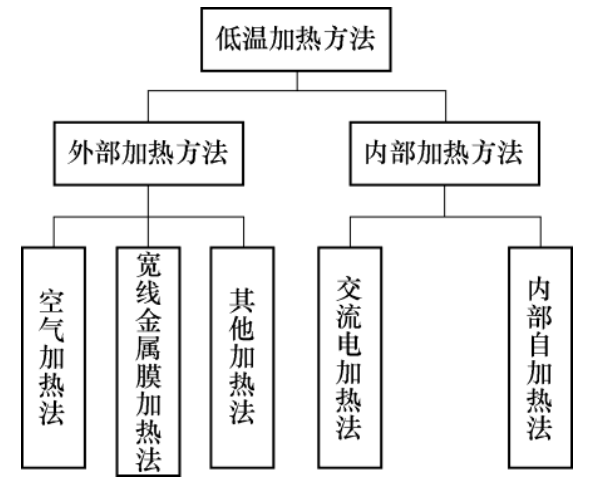

图 1 低温加热方法

空气加热法是一种先对空气进行加热, 再通过 热空气对动力电池组进行加热的方法, 由于空气与 电池接触较为均匀, 因此在加热过程中电池的温差 较小; 该方法的劣势在于加热速率较低, 难以满足 动力电池低温使用的需求。宽线金属膜加热法是一 种通过电流流经覆盖在电池表面的宽线金属膜时 产生的热量对动力电池进行加热的方法, 由于本文 采用的宽线金属膜的厚度只有 $0.04 \mathrm{~mm}$, 可以覆盖 在电池表面, 不影响电池箱结构, 因此无需重新设 计电池; 该方法的加热速率相较于空气加热法有较 大提升, 但仍难以满足需求。除上述两种外, 外部 加热方法还包括较为少见的帕尔贴效应加热法和 热洜加热法等低温加热方法, 帕尔贴效应加热法是 一种利用帕尔贴效应对动力电池进行加热的方法; 热原加热法是一种利用热原原理, 通过消耗电能从 外界空气中获取热量对电池进行加热的方法。这两 种方法都可以实现从低温处获取热量对高温处进 行加热, 但其加热速率和加热效率较低, 难以实现 车用。

交流电加热法是一种通过交流电流经电池时产 生的热量对电池内部进行加热的方法 ${ }^{[5]}$ 。交流加热 的研究历史较长, 加热效果较好, 目前采用交流加 热法的温升速率可以达到 $3{ }^{\circ} \mathrm{C} / \mathrm{min}$ 左右, 加热速率 较快; 但由于交流电源要克服电池本身电动势做功, 导致加热效率较低, 加热功耗过大。内部自加热法 是一种通过电流流经电池内部加设的镍片产生欧姆 热实现对电池自身加热的方法 ${ }^{[6-7]}$ 。该方法由美国宾 夕法尼亚州立大学王朝阳教授提出, 试验表明该方 法可以在 $1 \mathrm{~min}$ 以内将动力电池从 $-30{ }^{\circ} \mathrm{C}$ 加热到 $0{ }^{\circ} \mathrm{C}$ 以上, 温升速率极高; 但是由于该方法需要改 变电池结构, 其商业化难度较大。

目前国内外对于动力电池低温加热的研究仍显 不足, 加热效果尚未达到预期水平, 且仍存在加热 速率低、效率低、效果一致性差等问题。

大量的研究及试验结果显示, 单一模式的低温
加热方式难以达到理想的加热效果, 因此, 为兼顾 加热速率和效率，并保证实车应用的可行性，本 文提出一种综合了宽线金属膜加热法和交流电加 热法的复合加热方法。试验结果表明, 该方法可 以有效兼顾电池低温加热过程对高加热速率和高 加热效率的双重需求, 为低温加热研究提供了一 种新思路。

\section{1 加热策略}

宽线金属膜加热法是指在动力电池侧面加装 宽线金属膜进行加热的加热方式，宽线金属膜由 金属铜制成，本文采用的宽线金属膜使用折线的 形状, 在保证宽线金属膜的电阻较大的同时加大了 其与动力电池的接触面积, 提升了加热的均匀性。 宽线金属膜厚度为 $0.04 \mathrm{~mm}$, 正视图及实物图如 图 2 所示。

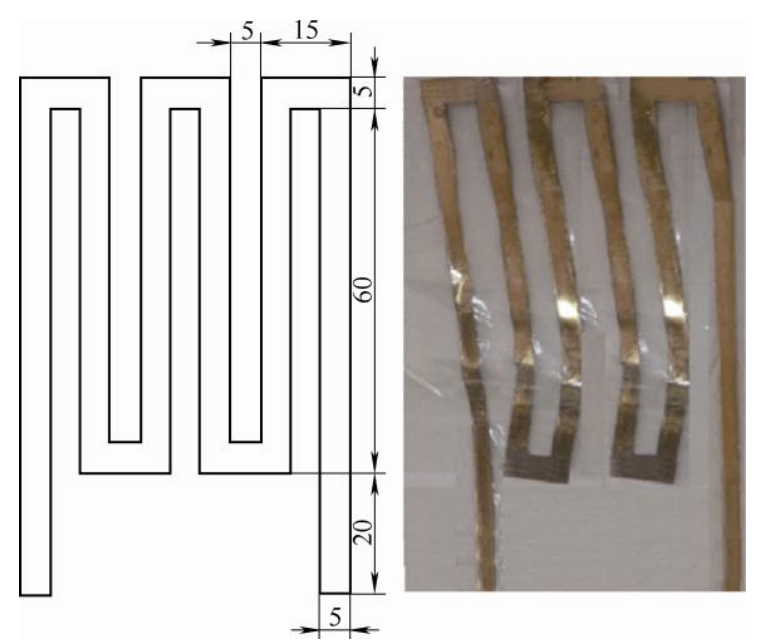

图 2 宽线金属膜正视图及实物图 $(\mathrm{mm})$

交流加热法分为梯次电流法和恒压法, 其中 恒压法由于电池的端电压随温度变化而变化, 导 致电池在低温加热过程中进行了充放电, 影响电 池安全, 因此本文采用梯次电流法, 试验流程图 如图 3 所示。

本文提出的复合加热法将动力电池与宽线金属 膜进行串联(图 4), 宽线金属膜与动力电池紧密贴 合, 两者通过导线连接。在需要进行低温加热时, 外部电源施加的交流电流经动力电池和宽线金属膜 进行产热, 实现对动力电池的加热。

该复合加热法通过温控开关控制电流是否流经 宽线金属膜。当温度较低, 需要进行低温加热时, 温控开关断开, 宽线金属膜与动力电池串联，外部 电源施加交流电进行产热。当温度较高, 无需进行 加热或电池需要正常充放电时, 温控开关闭合, 此 


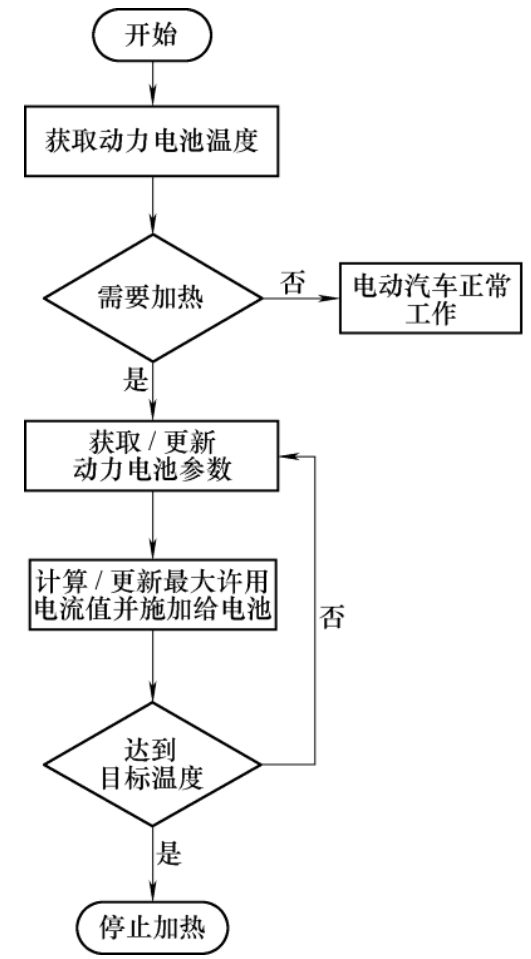

图 3 交流加热流程图

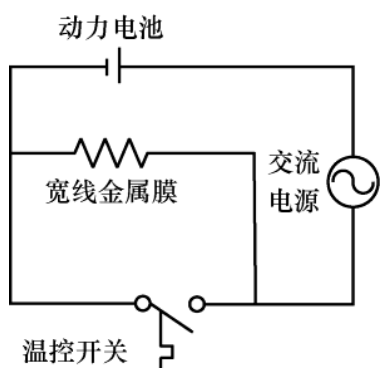

图 4 低温复合加热结构示意图

时宽线金属膜被短路, 动力电池可正常进行充放电, 实现了对动力电池低温加热的可控性。同时, 对于 内阻偏差较大的电池, 可以通过相应地调整宽线金 属膜的厚度或调整电路与宽线金属膜的连接位置, 改变宽线金属膜的电阻从而调整宽线金属膜的产热 率, 实现对内阻不一致电池的一致加热。

\section{2 理论模型}

本文以圆柱形锂离子动力电池为例进行仿真及 试验研究。

\section{1 锂离子动力电池的温升模型}

由于圆柱形锂离子动力电池体积较小, 其内部 和表面温升速率相差不大, 因此可认为在加热过程 中, 电池整体温度保持一致 ${ }^{[8-10]}$ 。因此, 圆柱形锂 离子动力电池的温升速率

$$
m c_{\mathrm{p}} \frac{\partial T_{\text {bat }}}{\partial t}=\dot{Q}-\dot{Q}_{\mathrm{n}}
$$

式中, $m$ 为电池质量, $c_{\mathrm{p}}$ 为电池比热容, $T_{\text {bat }}$ 为电
池温度, $t$ 为时间, $\dot{Q}$ 为总产热速率, $\dot{Q}_{\mathrm{n}}$ 为散热速 率，其中 $\dot{Q}_{\mathrm{n}}$ 的计算公式为

$$
\dot{Q}_{\mathrm{n}}=h S\left(T_{\text {bat }}-T_{\text {amb }}\right)
$$

式中, $h$ 为电池与环境的热交换系数, $S$ 为电池表 面积, $T_{\mathrm{amb}}$ 为环境温度。

电池产热速率包含两部分, 即电池内部产热及 宽线金属膜产热，其表达式分别如下

$$
\begin{aligned}
\dot{Q} & =\dot{Q}_{\mathrm{Cu}}+\dot{Q}_{\mathrm{bat}} \\
\dot{Q}_{\mathrm{bat}} & =\left(\frac{I}{\sqrt{2}}\right)^{2} R_{\mathrm{Q}} \\
\dot{Q}_{\mathrm{Cu}} & =\left(\frac{I}{\sqrt{2}}\right)^{2} R_{\mathrm{Cu}}
\end{aligned}
$$

式中, $\dot{Q}_{\mathrm{bat}}$ 为电池内部产热速率, $\dot{Q}_{\mathrm{Cu}}$ 为宽线金属膜 产热速率, $R_{\mathrm{Q}}$ 为电池阻抗(可由 $\mathrm{EIS}$ 离线获得), $R_{\mathrm{Cu}}$ 为宽线金属膜电阻, $I$ 为交流电幅值。

\section{2 锂离子动力电池模型}

等效电路模型是一种常见的电池模型, 其中较 为常用的一阶 $\mathrm{RC}$ 模型可以反映电池内部参数变

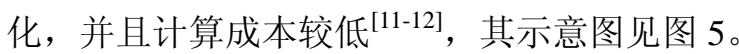

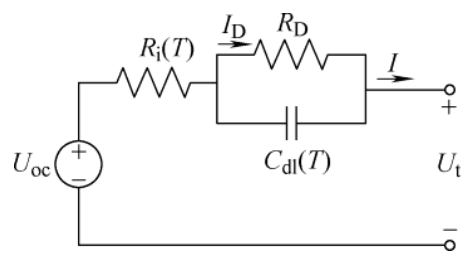

图 5 一阶 $\mathrm{RC}$ 模型示意图

结合 Butler-Volmer 方程与一阶 RC 模型，可以 得知电池电流与过电势的关系 ${ }^{[13]}$

$$
\begin{gathered}
I_{\mathrm{D}}=S_{\mathrm{a}} \bullet i_{0} \bullet\left[\exp \left(\frac{\alpha_{\mathrm{a}} \cdot F \bullet \eta}{R \cdot T}\right)-\exp \left(-\frac{\alpha_{\mathrm{c}} \cdot F \bullet \eta}{R \cdot T}\right)\right] \\
I=I_{\mathrm{D}}+C_{\mathrm{dl}} \frac{\mathrm{d} U_{\mathrm{ct}}}{\mathrm{d} t}
\end{gathered}
$$

式中, $S_{\mathrm{a}}$ 为电极活性面积, $\alpha_{\mathrm{a}} 、 \alpha_{\mathrm{c}}$ 分别为电池正 负极的电子传递系数, $i_{0}$ 为交换电流密度, $F$ 为法 拉第常数, $R$ 为气体常数, $\eta$ 为过电势, $C_{\mathrm{dl}}$ 为一阶 $\mathrm{RC}$ 模型中的电池电容值。

\section{3 仿真分析}

本文以镍钴锰三元锂离子动力电池为研究对象, 选用的电池参数如表 1 所示。此外，为尽可能地缩小 锂离子动力电池在加热过程中的内外温差, 宽线金属 膜的电阻值与锂离子动力电池的欧姆阻抗相近, 因此 试验过程中选用的宽线金属膜电阻为 $40 \mathrm{~m} \Omega$ (在 $25{ }^{\circ} \mathrm{C}$ 下测得); 由于交流电频率较低时可能导致动力电池负 
极析锂 ${ }^{[13]}$, 输出的正弦交流电的频率为 $530 \mathrm{~Hz}$ 。

表 1 本文所选电池参数

\begin{tabular}{cc}
\hline 名称 & 参数 \\
\hline 电池类型 & 18650 圆柱形电池 \\
负极材料 & $\mathrm{LiMnNiCoO}_{2}$ \\
正极材料 & 石墨 \\
标称容量 $/ \mathrm{A} \cdot \mathrm{h})$ & 3 \\
标准电压 $/ \mathrm{V}$ & 3.7 \\
上截止电压 $/ \mathrm{V}$ & 4.2 \\
下截止电压 $/ \mathrm{V}$ & 3.0 \\
长度 $/ \mathrm{mm}$ & 65 \\
直径 $/ \mathrm{mm}$ & 18 \\
质量 $/ \mathrm{g}$ & 46.0 \\
比热容 $/[\mathrm{J} /(\mathrm{g} \cdot \mathrm{K})]$ & 1.72 \\
\hline
\end{tabular}

为明确锂离子动力电池的最终温升预期, 需 要分别获取该复合加热系统在不同温度、交流电 幅值下锂离子动力电池和宽线金属膜的产热速率, 因此需要获得在 $530 \mathrm{~Hz}$ 下可以施加给锂离子动力 电池的最大许用电流, 通过对锂离子动力电池在不 同温度下开展电化学阻抗谱试验可以获取其参 数, 从而计算该动力电池在不同温度下的最大许用 电流。

\section{1 温度对电池阻抗的影响}

为获取锂离子动力电池在不同温度下的各项参 数, 开展了从 $-20 \sim 2{ }^{\circ} \mathrm{C}$ 的电化学阻抗(Electrochemical impedance spectroscopy, EIS)试验, 每隔 $2{ }^{\circ} \mathrm{C}$ 进行 一次试验, 并将此离线数据预存到电池管理系统中, 以计算不同温度下的最大许用电流幅值。试验结果 如图 6a 及图 6b 所示。

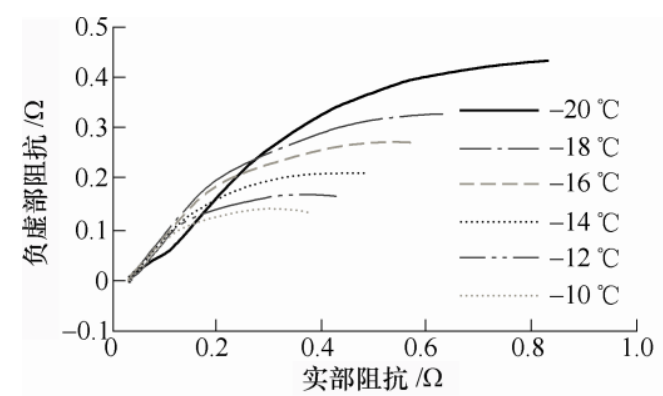

(a) $-20{ }^{\circ} \mathrm{C} \sim-10{ }^{\circ} \mathrm{C}$

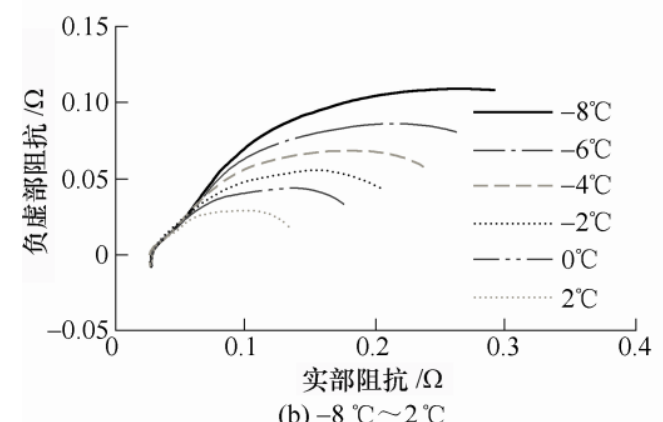

图 6 EIS 测试结果
基于 EIS 数据进行参数辨识, 获得了动力电池 在不同温度下的各项参数值, 为下一步的最大许用 电流值的计算提供模型基础。

\section{2 温度对电池最大许用电流值的影响}

由第 3.1 节获到的试验数据可辨识得到该动力 电池在 $-20 \sim 2{ }^{\circ} \mathrm{C}$ 的参数, 结合第 2.2 节中建立的锂 离子动力电池一阶 $\mathrm{RC}$ 模型, 计算在不同温度下锂 离子动力电池的最大许用电流值。为保证电池加热 过程的安全性, 电池电压应始终处于上/下截止电压 之间, 且最大电流值小于 $10.5 \mathrm{~A}(3.5 \mathrm{C})$, 最终结果 如图 7 所示。

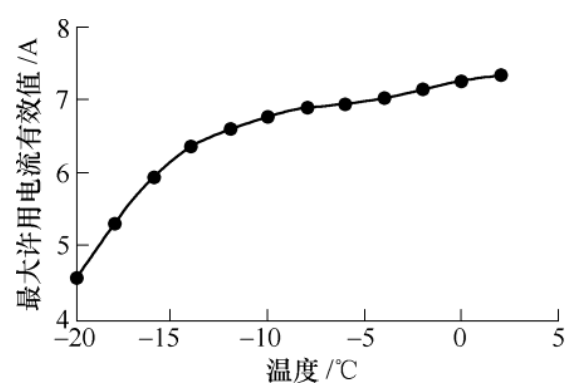

图 7 最大许用电流有效值与温度关系

\section{3 温度对电池与宽线金属膜产热率的影响}

将第 3.2 节中获取到的该锂离子动力电池在不 同温度下的最大许用电流值及宽线金属膜电阻随温 度的变化情况，可以计算获得在不同温度下宽线金 属膜的产热率, 如图 8 所示。

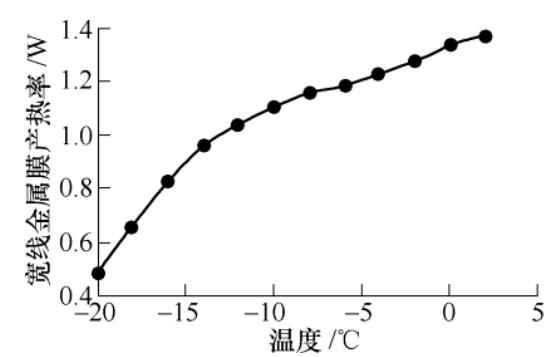

图 8 宽线金属膜产热率与温度关系

利用式(4)、(6)，并结合第 3.2 节中获取到的最 大许用电流值及第 3.1 节中获取到的该电池在不同 温度下的各项参数, 可以计算获得在不同温度下锂 离子动力电池本身的产热率(图 9)。

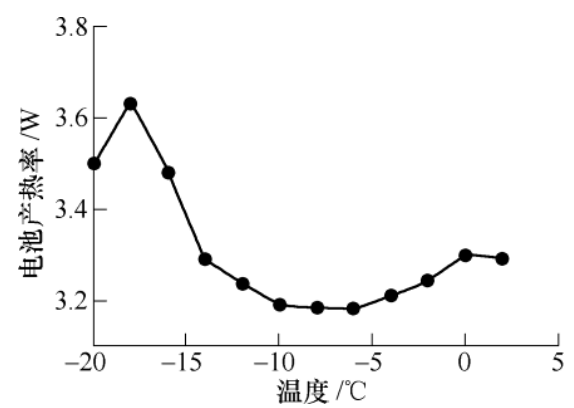

图 9 电池产热率与温度关系 


\section{4 电池温升仿真结果}

结合第 3.3 节中获取的电池与宽线金属膜的产 热率和第 2.1 节的电池温升模型, 综合加热过程中 产热及散热过程可以获取到该复合加热系统的整体 产热率减去散热率 $\left(P_{\mathrm{all}}\right)$ 的结果(图 10$)$ 。

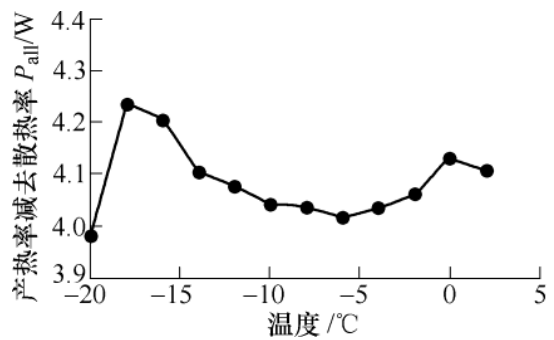

图 $10 P_{\text {all }}$ 与温度关系

加热过程采用每隔 $2{ }^{\circ} \mathrm{C}$ 调整一次加热电流幅 值的方式, 根据 $P_{\text {all }}$ 与温度的关系, 再结合电池质 量、比热容等物理参数, 可获得电池的温升仿真结 果, 如图 11 所示。

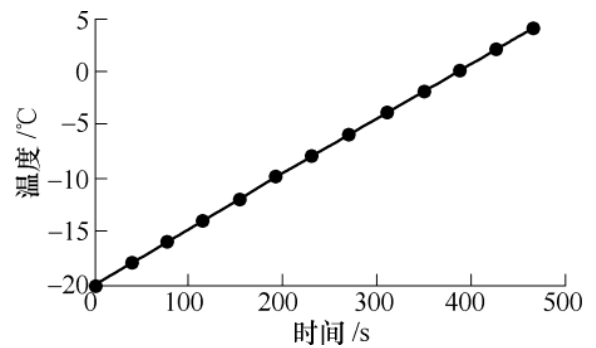

图 11 电池温升仿真结果

\section{4 试验}

以 18650 型镍钴锰三元锂离子动力电池单体开 展了交流电加热宽线金属膜加热与复合加热法的对 比试验。使用图 12 所示的硬件平台, 交流电源提供 交流电对电池进行加热; 电化学工作站对电池进行 EIS 试验获取电化学阻抗谱随温度的变化情况; 恒 温箱提供稳定的低温外部环境; 充放电设备实时测 量电流、电压、温度。

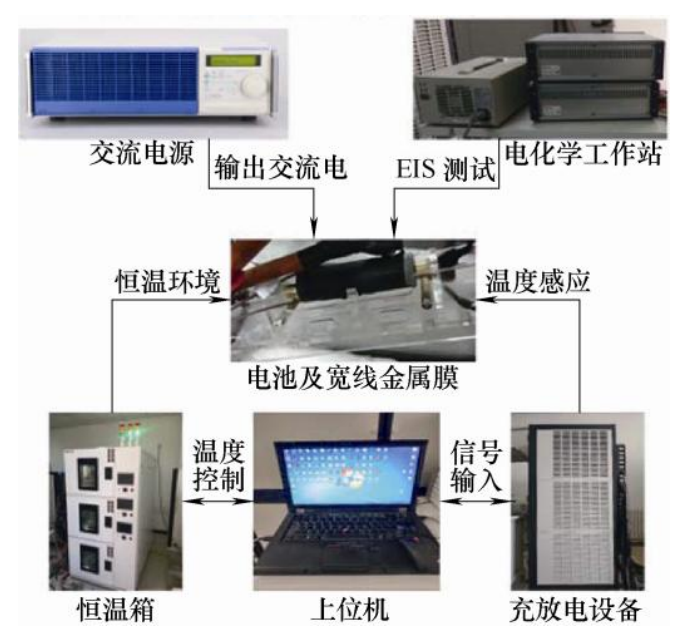

图 12 低温复合加热测试平台
为研究复合加热方法在低温环境下的加热效 果, 将 1 块 18650 型镍钴锰三元锂离子动力电池与 宽线金属膜进行串联后再与交流电源相接(图 13)。 电池被放置在温度设置为 $-20{ }^{\circ} \mathrm{C}$ 的恒温箱中，表面 覆盖保温层进行保温。为保证动力电池内部温度的 均一性和准确性, 将动力电池静置 $5 \mathrm{~h}$ 后, 再接通 电源进行加热。

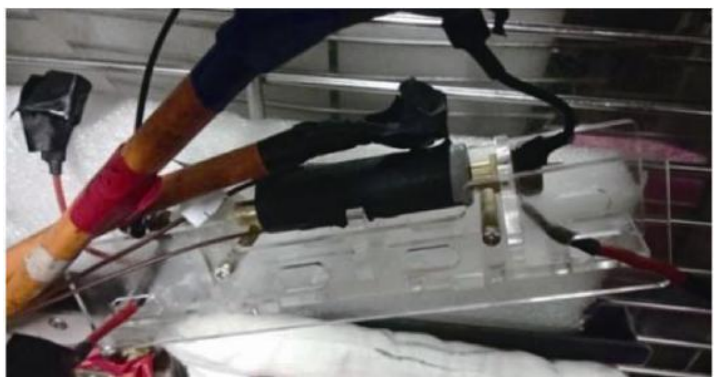

图 13 交流加热实物图

将热电偶布置在电池侧面, 通过温度传感器观 测电池温度, 并根据动力电池温度调整交流电源输 出电流的幅值, 记录电池温度随时间的变化情况。 动力电池温升仿真结果与试验结果如图 14 所示。加 热过程共计 $471 \mathrm{~s}$, 期间动力电池温度共上升了 $25.1{ }^{\circ} \mathrm{C}$, 平均温升速率为 $3.20{ }^{\circ} \mathrm{C} / \mathrm{min}$ 。同时, 从 图 14 还可以看出该低温复合加热法的仿真结果与 试验结果较为接近, 最大温度估计误差在 $2{ }^{\circ} \mathrm{C}$ 以 内, 具有较好的仿真效果。

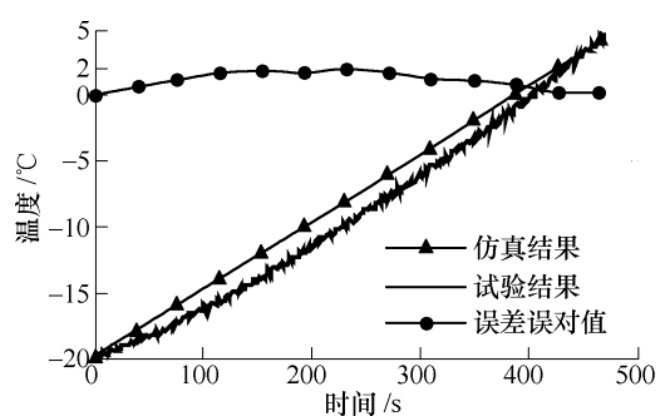

图 14 电池温升试验结果与仿真结果对比图

三种加热方法的详细对比, 如表 2 所示, 只采 用交流电加热的试验结果表明, 将电池从- $20{ }^{\circ} \mathrm{C}$ 加 热至 $5{ }^{\circ} \mathrm{C}$ 需要 $575 \mathrm{~s}$, 平均温升速率为 $2.62{ }^{\circ} \mathrm{C} / \mathrm{min}$ 。 而采用相同许用电流-温度曲线的宽线金属膜加热 法将电池从 $-20{ }^{\circ} \mathrm{C}$ 加热至 $5{ }^{\circ} \mathrm{C}$ 需要 $2208 \mathrm{~s}$, 平均温 升速率为 $0.68{ }^{\circ} \mathrm{C} / \mathrm{min}$ 。

通过记录交流电源的输出电压和输出电流并进 行计算可得不同加热策略在加热过程中的能耗，采 用复合加热法将动力电池从 $-20{ }^{\circ} \mathrm{C}$ 加热到 $5{ }^{\circ} \mathrm{C}$ 消 耗了 $3.40 \mathrm{~W} \cdot \mathrm{h}$, 单独交流电加热法消耗了 $4.40 \mathrm{~W} \cdot \mathrm{h}$ 的能量, 可见, 该复合加热法相较于传统交流电加 热法降低了 $23 \%$ 的加热能耗。采用相同许用电流- 
温度曲线的宽线金属膜加热法将同一动力电池从 $-20{ }^{\circ} \mathrm{C}$ 加热至 $5{ }^{\circ} \mathrm{C}$ 需要消耗 $1.20 \mathrm{~W} \cdot \mathrm{h}$ 的能量。

表 2 复合加热法与交流电加热法加热效果比较

\begin{tabular}{lccc}
\hline 参数 & $\begin{array}{c}\text { 交流电 } \\
\text { 加热法 }\end{array}$ & $\begin{array}{c}\text { 宽线金属膜 } \\
\text { 加热法 }\end{array}$ & $\begin{array}{c}\text { 复合 } \\
\text { 加热法 }\end{array}$ \\
\hline 温升速率 $/\left({ }^{\circ} \mathrm{C} / \mathrm{min}\right)$ & 2.62 & 0.68 & 3.20 \\
$-20{ }^{\circ} \mathrm{C}$ 至 $5{ }^{\circ} \mathrm{C}$ 消耗功 $/(\mathrm{W} \cdot \mathrm{h})$ & 4.40 & 1.20 & 3.40 \\
\hline
\end{tabular}

为研究该复合加热法对电池组的加热效果, 选 择具有单体内阻不一致的串联动力电池组开展研 究。选用了同批次下老化后的三元组离子动力电池, 其在 $25{ }^{\circ} \mathrm{C}$ 下的欧姆阻抗为 $60 \mathrm{~m} \Omega$, 对该老化电池 分别开展了未修正和修正后的低温加热试验。修正 方法为通过调整电路与宽线金属膜的接触位置以改 变接入电路的宽线金属膜电阻, 本文调整为 $10 \mathrm{~m} \Omega$ 的接入电阻。

将新旧两块电池进行串联, 最大许用电流以新 电池计算结果为准, 试验结果如图 15 所示。

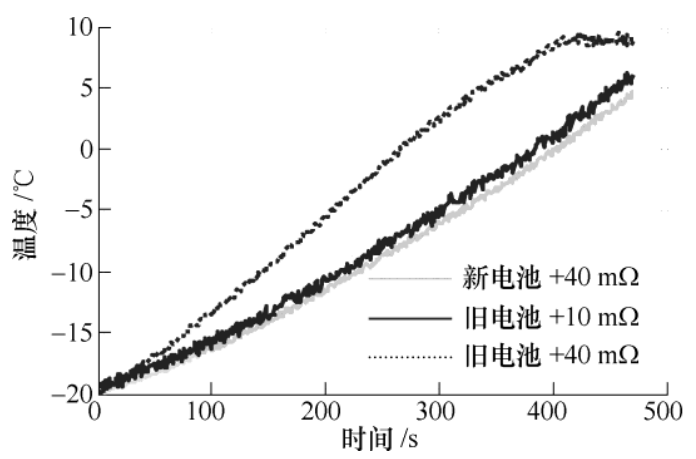

图 15 新老电池与不同阻值宽线金属膜组合试验结果

可以看出，通过对宽线金属膜电阻值的调整， 可以在很大程度上缓解由于动力电池单体之间内阻 一致性较差导致的电池温升速率不一致的问题, 新 老电池之间的最大温差由 $9.03{ }^{\circ} \mathrm{C}$ 降低至 $1.86{ }^{\circ} \mathrm{C}$ 。

\section{5 结论}

本文针对锂离子动力电池低温充放电性能差的 问题, 提出了采用交流电内部电加热和宽线金属膜 外部加热相结合的复合加热方法。建立了锂离子动 力电池的温升模型, 基于动力电池在不同温度下的 EIS 试验计算得到了最大许用加热电流。动力电池 低温复合加热试验结果表明该方法在加热速率、效 率和一致性上均有提升，具体结论如下。

(1) 该复合加热法相较于传统的加热方法具有 更高的加热速率，相较于交流电加热法提升了 $22 \%$ 的加热速率, 相较于宽线金属膜加热法提升了 $371 \%$ 的加热速率, 能在更短的时间内将动力电池加热至
需要的温度, 改善动力电池低温使用环境。

(2) 该复合加热法相较于传统的交流电加热方 法具有更低的加热能耗，降低了 $23 \%$ 的加热过程能 耗, 耗电量低。

（3）该复合加热法能够克服串联电池组加热不 一致的问题, 对于单体内阻显著差异的动力电池组, 具有较好的调整能力并保证温升的同步性。

\section{参 考 文 献}

[1] LEI Zhiguo, ZHANG Yuwen, LEI Xueguo. Temperature uniformity of a heated lithium-ion battery cell in cold climate[J]. Applied Thermal Engineering, 2018, 129: 148-154.

[2] TSAI W C, RIZVI S S H. Liposomal microencapsulation using the conventional methods and novel supercritical fluid processes[J]. Trends in Food Science \& Technology, 2016, 55: 61-71.

[3] PARK G, GUNAWARDHANA N, NAKAMURA H, et al. The study of electrochemical properties and lithium deposition of graphite at low temperature[J]. Journal of Power Sources, 2012, 199: 293-299.

[4] AHMAD A P, ANDREAS V, THOMAS S. Cooling and preheating of batteries in hybrid electric vehicles[C]//The 6th ASME-JSME Thermal Engineering Joint Conference, 2003: $1-7$.

[5] ZHANG Jianbo, GE Hao, LI Zhe, et al. Internal heating of lithium-ion batteries using alternating current based on the heat generation model in frequency domain[J]. Journal of Power Sources, 2015，273: 1030-1037.

[6] WANG Chaoyang, LIU Ming, LI Bingxin, et al. Thermodynamic analysis on the transient cycling of coal-fired power plants: Simulation study of a $660 \mathrm{MW}$ supercritical unit[J]. Energy, 2017，122: 505-527.

[7] JI Yan, WANG Chaoyang. Heating strategies for Li-ion batteries operated from subzero temperatures[J]. Electrochimica Acta， 2013， 107: 664-674.

[8] LI Junqiu, SUN Danni. Lithium-ion batteries modeling and optimization strategies for sinusoidal alternating current heating at low temperature[J]. Energy Procedia, 2018, 152: 562-567.

[9] LI Zhe, ZHANG Jianbo, WU Bin, et al. Examining temporal and spatial variations of internal temperature in large-format laminated battery with embedded thermocouples[J]. Journal of Power Sources，2013，241: 536-553.

[10] JIANG Jiuchun, RUAN Haijun, SUN Bingxiang, et al. A low-temperature internal heating strategy without lifetime reduction for large-size automotive lithium-ion battery 
pack[J]. Applied Energy， 2018， 230: 257-266.

[11] DEES D W, VINCENT S B. Electrochemical modeling of lithium polymer batteries[J]. Journal of Power Sources, 2002(110): 310-320.

[12] LI Xinggang, XIONG Rui. Modeling and optimization of heat dissipation structure of EV battery pack[J]. Journal of Beijing Institute of Technology, 2018, 27(1): 29-35.

[13] GUO Shanshan, XIONG Rui, WANG Kan, et al. A novel echelon internal heating strategy of cold batteries for all-climate electric vehicles application[J]. Applied Energy, 2018, 219: 256-263.

作者简介: 熊瑞(通信作者), 男, 1985 年出生, 教授, 博士研究生导师。 主要研究方向为电动汽车动力电池系统管理与综合控制。

E-mail: rxiong@bit.edu.cn

王㑆, 男, 1994 年出生, 硕士研究生。主要研究方向为动力电池低温加热。 E-mail: wkan1994@163.com

郭姗姗, 女, 1985 年出生, 博士研究生。主要研究方向为动力电池低温 加热。

E-mail: lucy001478@163.com 